\title{
El diseño web como factor de integración de las personas con discapacidad
}

\author{
The web design as factor of integration of persons with disabilities
}

\author{
M.Sc. Patricia MADRIGAL BARRÓN \\ Universidad Rey Juan Carlos (URJC), España \\ patricia.madrigal@urjc.es \\ M.Sc. Elena CARRILLO PASCUAL \\ Universidad Rey Juan Carlos (URJC), España \\ e.carrillo.pascual@gmail.com \\ Dra. Belén PUEBLA MARTíNEZ \\ Universidad Complutense de Madrid (UCM), España \\ bpuebla@ucm.es
}

\section{Resumen}

La diversidad caracteriza a los seres humanos. Como aluden los dichos antiguos, cada uno somos un mundo y colores hay para cada uno. Ésta es una premisa que no debe olvidarse en diseño. Es fundamental adaptarse a la diversidad humana, fomentando la accesibilidad y el diseño para todos.

El término accesibilidad se ha utilizado con frecuencia en arquitectura y urbanismo, pero menos familiarizados estamos con hacer de Internet un entorno de uso universal. Este trabajo tiene como objetivo analizar la importancia de diseñar cumpliendo las Directrices de Accesibilidad para el Contenido en la Web del W3C, que permiten a las personas con discapacidad acceder fácilmente a la información web. Se hará un estudio de las pautas que marcan estas Directrices, los beneficios de fomentar su aplicación y se mostrarán buenas prácticas, ejemplo de un camino a recorrer diseñado teniendo en cuenta a todas las 
personas, independientemente de las capacidades funcionales que presenten, porque sólo así trabajaremos en pro de la igualdad y la integración.

\section{Abstract}

The diversity is a quality of human being. Each person is a world and there are colors for each and every one of them. The design has to keep in mind to this premise. It is fundamental the adaptation to the human diversity, and it is encouraged the accessibility and universal design.

The term accessibility has been frequently used in architecture and urban planning, but it has been seldom used in design web. It is necessary to think about Internet and accessibility, and to create universal virtual settings. This article analyses the importance of design meets the Web Content Accessibility Guidelines of the W3C. These guidelines explain how to make web content accessible to persons with disabilities. This paper studies those standards and the benefits of using them, and it shows good practice cases of universal design. Instructions and examples of web accessibility, which contributes to the equality and integration of persons with disabilities.

Palabras Clave: Diseño Web, Accesibilidad, Internet, Discapacidad.

Key Words: Web Design, Accessibility, Internet, Disability.

\section{Introducción. La importancia de la accesibilidad web en el proceso de integración de las personas con discapacidad}

Las personas con discapacidad se han visto abocadas, a lo largo de la historia, a vivir un proceso de exclusión social del que fueron saliendo lentamente el siglo pasado, y cuya tendencia, hoy en día, continúa. Desde los tiempos de maleficios y brujos con los que se asociaba la discapacidad en la Edad Antigua, o la consideración de una enfermedad vergonzosa para las familias -y por ello oculta- de tiempos no tan lejanos, ha habido muchos avances en el proceso de integración de las personas con discapacidad, pero todavía queda un camino por recorrer.

Debido a la importancia de Internet en la sociedad actual, hoy en día vivimos conectados a la red, tanto en el ámbito profesional como en el personal. Este hecho se ha convertido en una necesidad para todos, incluidas las personas con discapacidad. Los progresos hechos en la 
integración del colectivo pasan ahora por esta nueva realidad que es Internet. La accesibilidad web y el diseño para todos se convierten en los nuevos objetivos a perseguir.

La Convención sobre los Derechos de las Personas con Discapacidad de las Naciones Unidas define el diseño universal como:

"El diseño de productos, entornos, programas y servicios que puedan utilizar todas las personas, en la mayor medida posible, sin necesidad de adaptación ni diseño especializado. El 'diseño universal' no excluirá las ayudas técnicas para grupos particulares de personas con discapacidad, cuando se necesiten" (2006: 5).

La Convención "prevé medidas, tanto de no discriminación como de acción positiva, que los Estados deberán implantar para garantizar que las personas con discapacidad puedan disfrutar de sus derechos en igualdad de condiciones que las demás personas" (Anula, 2011: 3). El artículo 9 de dicha Convención propone medidas en cuestión de accesibilidad:

1. A fin de que las personas con discapacidad puedan vivir de forma independiente y participar plenamente en todos los aspectos de la vida, los Estados Partes adoptarán medidas pertinentes para asegurar el acceso de las personas con discapacidad, en igualdad de condiciones con las demás, al entorno físico, el transporte, la información y las comunicaciones, incluidos los sistemas y las tecnologías de la información y las comunicaciones, y a otros servicios e instalaciones abiertos al público o de uso público, tanto en zonas urbanas como rurales. Estas medidas, que incluirán la identificación y eliminación de obstáculos y barreras de acceso, se aplicarán, entre otras cosas, a:

a) Los edificios, las vías públicas, el transporte y otras instalaciones exteriores e interiores como escuelas, viviendas, instalaciones médicas y lugares de trabajo;

b) Los servicios de información, comunicaciones y de otro tipo, incluidos los servicios electrónicos y de emergencia.

2. Los Estados Partes también adoptaran las medidas pertinentes para:

a) Desarrollar, promulgar y supervisar la aplicación de normas mínimas, directrices sobre la accesibilidad de las instalaciones y los servicios abiertos al público o de uso público;

b) Asegurar que las entidades privadas que proporcionan instalaciones y servicios abiertos al público o de uso público tengan en cuenta todos los aspectos de su accesibilidad para las personas con discapacidad;

c) Ofrecer formación a todas las personas involucradas en los problemas de accesibilidad a que se enfrentan las personas con discapacidad; 
d) Dotar a los edificios y otras instalaciones abiertas al público de señalización en braille y en formatos de fácil lectura y comprensión;

e) Ofrecer formas de asistencia humana o animal e intermediarios, incluidos guías, lectores e intérpretes profesionales de la lengua de señas, para facilitar el acceso a edificios y otras instalaciones abiertas al público;

f) Promover otras formas adecuadas de asistencia y apoyo a las personas con discapacidad para asegurar su acceso a la información;

g) Promover el acceso de las personas con discapacidad a los nuevos sistemas y tecnologías de la información y las comunicaciones, incluida Internet;

h) Promover el diseño, el desarrollo, la producción y la distribución de sistemas y tecnologías de la información y las comunicaciones accesibles en una etapa temprana, a fin de que estos sistemas y tecnologías sean accesibles al menor costo (ONU, 2006: 10-11).

En 2007, España ratificó la Convención de Naciones Unidas sobre los Derechos de las Personas con Discapacidad, siendo uno de los primeros países en hacerlo. "Desde su entrada en vigor el 3 de mayo de 2008, la Convención es vinculante jurídicamente para España, incorporándose a nuestro ordenamiento" (Anula, 2011: 3).

La regulación española sobre accesibilidad se contiene básicamente en la Ley 51/2003 de igualdad de oportunidades, no discriminación y accesibilidad universal (LIONDAU) de las personas con discapacidad y en las normas y planes que la desarrollan. La LIONDAU en su artículo 7 especifica como medida contra la discriminación las exigencias de accesibilidad, definidas éstas como "los requisitos que deben cumplir los entornos, productos y servicios, así como las condiciones de no discriminación en normas, criterios y prácticas, con arreglo a los principios de accesibilidad universal de diseño para todos" (Ley 51/2003: 43190). En el artículo 10 de la misma Ley se establecen las condiciones básicas de accesibilidad y no discriminación: "El Gobierno, sin perjuicio de las competencias atribuidas a las comunidades autónomas y a las corporaciones locales, regulará unas condiciones básicas de accesibilidad y no discriminación que garanticen unos mismos niveles de igualdad de oportunidades a todos los ciudadanos con discapacidad" (Ley 51/2003: 43190).

En relación al tema que nos ocupa, el diseño web, la LIONDAU se desarrolla en relación al tema en el Real Decreto 1494/2007 de 12 de noviembre, por el que se aprueba el Reglamento sobre las condiciones básicas para el acceso de las personas con discapacidad 
a las tecnologías, productos y servicios relacionados con la sociedad de la información y medios de comunicación social. En el capítulo III se establecen los Criterios y condiciones básicas de accesibilidad y no discriminación en materia de sociedad de la información, nos interesan especialmente los artículos de dicho capítulo:

Artículo 5. Criterios de accesibilidad aplicables a las páginas de Internet de las administraciones públicas o con financiación pública.

Artículo 6. Criterios de accesibilidad a otras páginas de Internet.

Artículo 7. Sistema de certificación de páginas de Internet.

Artículo 8. Condiciones básicas de accesibilidad a los equipos informáticos y a los programas de ordenador.

Artículo 9. Condiciones básicas de accesibilidad en materia de firma electrónica.

La accesibilidad web es, por tanto, una cuestión de ley. Además de una cuestión de derechos humanos, de sentido común y de conciencia. La vida de las personas con discapacidad puede mejorar por el simple hecho de tener acceso a la web. Por ejemplo, una persona ciega podría dejar de ser dependiente al tener la posibilidad de acceder en formato audio a la información de un periódico digital. Expertos aluden a Internet el poder de democratizar, sobre todo en la difusión de la información, pero esto sólo podrá ser cierto si se resuelven las desigualdades y, para ello, hay que permitir el acceso al contenido web a todos independientemente de las capacidades funcionales de cada uno. Las nuevas tecnologías de la información y la comunicación son una oportunidad para la integración de las personas con discapacidad. Es necesario hacer uso de esas tecnologías para reducir la brecha entre los que están y usan Internet y los que no.

Los encargados del diseño web, tal y como se recoge en la Convención sobre los Derechos de las Personas con Discapacidad, deben ser formados en diseño universal. Es imprescindible que tomen conciencia de la realidad de las personas con discapacidad. En el momento de diseñar se debe tener en cuenta la diversidad humana, saber que hay personas con diferentes capacidades funcionales, que podrían ser usuarios de los entornos web creados. Contamos con las herramientas que permiten que las personas con discapacidad puedan acceder al contenido web. Sólo es necesario utilizarlas. El diseño web debe marcarse ese objetivo, para ello, existen pautas consolidadas que guían en la elaboración de contenidos web de acceso universal. "Unos criterios de accesibilidad aplicables a las páginas de Internet son los que se recogen, a nivel internacional, en la Iniciativa de Accesibilidad a la 
Web (Web Accessibility Iniciative) del Consorcio Mundial de la Web (World Wide Web Consortium), que los ha determinado en forma de pautas comúnmente aceptadas en todas las esferas de Internet, como las especificaciones de referencia cuando se trata de hacer que las páginas de Internet sean accesibles a las personas con discapacidad. En función de dichas pautas, la Iniciativa de Accesibilidad a la Web ha determinado tres niveles de accesibilidad: básico, medio y alto, que se conocen como niveles $A, A A$ (o doble A) y AAA (o triple A). Dichas pautas han sido incorporadas en España a través de la Norma UNE 139803:2004, que establece tres niveles de prioridades" (Real Decreto 1494/2007: 47567). En los siguientes puntos de este texto, para servir de apoyo en el diseño web, nos ocuparemos específicamente de estas pautas que suponen un importante factor de integración.

Al permitir a las personas con discapacidad acceder al contenido web se les hace sujetos de un mismo entorno, cerrando una puerta que impide el paso a la exclusión. El diseño para todos es antónimo de segregación. La no accesibilidad es una forma sutil, pero muy eficaz de discriminación, "de discriminación indirecta en este caso, pues genera una desventaja cierta a las personas con discapacidad en relación con aquellas que no lo son, al igual que ocurre cuando una norma, criterio o práctica trata menos favorablemente a una persona con discapacidad que a otra que no lo es" (Ley 51/2003: 43188). Debemos luchar por la igualdad, no deben utilizarse fórmulas discriminatorias, es por ello que la accesibilidad debe ser una premisa a cumplir. Hemos conseguido que otros entornos tomen conciencia del papel que juega la accesibilidad, por ejemplo, se han producido avances importantes en la supresión de barreras arquitectónicas. Ahora que Internet es el nuevo entorno se debe luchar por la supresión de las barreras que impiden el acceso a las personas con discapacidad.

El diseño universal no sólo beneficia a las personas con discapacidad, otros usuarios y, los propietarios de los portales, también encuentran ventajas en el cumplimiento de las directrices de accesibilidad. Estos son algunos de los grupos de usuarios benefactores:

Cuadro 1. Usuarios beneficiarios accesibilidad Web 


\begin{tabular}{|c|c|c|c|c|}
\hline $\begin{array}{c}\text { Usuarios de } \\
\text { edad avanzada } \\
\text { con dificultades } \\
\text { producidas por } \\
\text { el } \\
\text { envejecimiento. }\end{array}$ & $\begin{array}{l}\text { Usuarios en } \\
\text { entornos } \\
\text { con baja } \\
\text { iluminación, } \\
\text { ambientes } \\
\text { ruidosos, } \\
\text { espacio } \\
\text { reducido, } \\
\text { etc. }\end{array}$ & $\begin{array}{l}\text { Usuarios } \\
\text { con } \\
\text { insuficiencia } \\
\text { de medios } \\
\text { que } \\
\text { acceden a } \\
\text { Internet } \\
\text { desde } \\
\text { equipos y } \\
\text { conexiones } \\
\text { limitadas. }\end{array}$ & $\begin{array}{l}\text { Usuarios } \\
\text { que no } \\
\text { dominan } \\
\text { el idioma. }\end{array}$ & $\begin{array}{c}\text { Usuarios } \\
\text { inexpertos o } \\
\text { que } \\
\text { presentan } \\
\text { inseguridad } \\
\text { frente a la } \\
\text { utilización } \\
\text { de } \\
\text { dispositivos } \\
\text { electrónicos. }\end{array}$ \\
\hline
\end{tabular}

Fuente: Universidad de Alicante

En cuento a las ventajas de la accesibilidad Web, se citan aquí algunos de los múltiples beneficios a usuarios y propietarios:

Cuadro 2. Ventajas de la accesibilidad Web

Mejora el posicionamiento web en los buscadores al aumentar el número de usuarios y, por tanto, de visitas.

Mayor indexación en los motores de búsqueda.

Se incrementa la cuota de mercado y audiencia en la web.

Maximización de los usuarios potenciales, mayor alcance de la comunicación, servicios o mercado.

Hoy, que las empresas se preocupan tanto de la triple cuenta de resultados; económica, social y medioambiental; la accesibilidad demuestra responsabilidad social. La eliminación de barreras en el acceso a la web evidencia preocupación y atención hacia todos los clientes. Lo que ayuda a mejorar la imagen de la empresa.

Se cumple con el derecho ciudadano a la participación y no discriminación por razón de discapacidad.

Evidencia el cumplimiento de la ley.

Al diseñar conforme a estándares de accesibilidad, garantizamos la equivalencia de los contenidos entre distintos navegadores y dispositivos. 
Al cumplir los estándares web, la página será visionada correctamente desde cualquier navegador.

No se renuncia a la creatividad, este es un mito extendido, pero erróneo.

Aumenta la usabilidad de la página con los beneficios que ello supone.

Mejora la eficiencia y el tiempo de respuesta. Las páginas están limpias de código inútil y poco eficiente y pesan menos, disminuyendo el tiempo de carga.

Se pueden obtener ayudas y subvenciones.

Disminuyen los costes de desarrollo y mantenimiento. En los inicios aprender a hacer una página web accesible supondrá un coste, pero una vez que se tienen los conocimientos, el coste de desarrollar y mantener la web será menor en comparación con una web no accesible, porque una página accesible está bien hecha y es menos propensa a contener errores y más sencilla de actualizar.

\section{Fuente: Universidad de Alicante}

Si se puede, no es costoso, las ventajas son cuantiosas y los beneficiarios múltiples no hay razón para no seguir las pautas de diseño web universal. La accesibilidad web resultante fomentará la construcción de una sociedad más democrática, justa, igualitaria y se avanzará en términos de inclusión social.

\section{Las Directrices de Accesibilidad para el Contenido en la Web del W3C}

El World Wide Web Consortium (W3C) fue creado en 1994 de la mano de Tim Berners-Lee en el laboratorio de Ciencias Informáticas del Instituto de Tecnología de Massachusetts. Se trata de una comunidad internacional que lleva a cabo estándares que aseguran el desarrollo de la web a largo plazo.

De esta forma, y gracias al trabajo conjunto de sus agentes sociales, el W3C logra crear estándares web con el principal objetivo de guiar hacia el máximo potencial. De esta manera, podríamos decir que la principal actividad de W3C es el desarrollo de protocolos y directrices que definen las partes claves de la World Wide Web. Esta actividad se guía por dos principios: 
Cuadro 3. Principios en los que se basa W3C

\begin{tabular}{|c|c|}
\hline Web para todo el mundo & Web desde cualquier dispositivo \\
\hline $\begin{array}{c}\text { Conseguir que el valor social que aporta } \\
\text { la web esté disponible para todo el } \\
\text { mundo, independientemente del } \\
\text { hardware, software, infraestructuras, } \\
\text { idioma, cultura, localización o habilidades } \\
\text { físicas o mentales. }\end{array}$ & $\begin{array}{c}\text { Accesibilidad a la web desde cualquier } \\
\text { dispositivo (móvil, PDA, sistemas de } \\
\text { respuesta interactiva). }\end{array}$ \\
\hline
\end{tabular}

Fuente: W3C

La visión del W3C se divide en tres prioridades básicas:

Cuadro 4. Prioridad en las que se basa la visión de W3C

\begin{tabular}{|lr|l|l|}
\hline $\begin{array}{l}\text { Web de los autores y } \\
\text { consumidores }\end{array}$ & $\begin{array}{l}\text { Web de los datos y } \\
\text { servicios }\end{array}$ & Web de confianza \\
\hline $\begin{array}{l}\text { La web es una } \\
\text { herramienta }\end{array}$ & $\begin{array}{l}\text { Ambas visiones (web de } \\
\text { comunicación yacenamiento o de de } \\
\text { creación de contenido. de }\end{array}$ & $\begin{array}{l}\text { Para apoyar interacciones } \\
\text { complejas entre distintas } \\
\text { servicios) necesitan } \\
\text { distintos requisitos y } \\
\text { aplicaciones tecnológicas. }\end{array}$ & \\
partes del mundo.
\end{tabular}

Fuente: W3C

\subsection{Directrices de accesibilidad de la W3C}

Dentro de las prioridades referidas a la 'Web de los autores y consumidores' encontramos las directrices acerca de la accesibilidad en la Web. Tal y como afirma Tim Berners-Lee": "The power of the Web is in its universality. Access by everyone regardless of disability is an essential aspect". 2

En este sentido el W3C trabaja para que cualquier persona, independientemente de su capacidad física o mental pueda acceder a esta herramienta. La misión de la Iniciativa de

\footnotetext{
${ }^{1}$ Ver en: http://www.w3 .org/standards/Webdesign/accessibility

${ }^{2}$ El poder de la web está en la universalidad. El acceso de cualquiera, independientemente de su discapacidad, es un aspecto especial.
} 
Accesibilidad Web (WAl) es conseguir que la web desarrolle su máximo potencial de accesibilidad, permitiendo a las personas con discapacidad participar e interactuar de manera igualitaria en la web. De esta manera, como ya hemos expresado, se apoya la inclusión social no sólo de las personas con discapacidad, sino de las personas mayores, las personas que viven en áreas rurales o las personas que viven en países en vías de desarrollo.

Además, los estudios respaldan las ventajas que se han citado anteriormente, es decir, los sitios web accesibles tienen mejores resultados de búsqueda, costes de mantenimiento reducidos, y un mayor alcance de público, entre otras. Sin embargo, muchos sitios o instrumentos web aún se desarrollan con barreras de accesibilidad, lo que dificulta o incluso imposibilita su utilización por algunas personas.

En este sentido, debemos señalar que la accesibilidad web depende de varios elementos que trabajan conjuntamente, por lo que la mejora de estos podría aumentar la accesibilidad web. Estos componentes incluyen: el contenido, los navegadores web, los complementos tecnológicos, el conocimiento de los usuarios, diseñadores web, herramientas de creación y evaluación de páginas web.

Existe una interdependencia significativa entre estos componentes, es decir, estos componentes deben trabajar juntos para que la web sea accesibles (Imagen 1): Relación entre los componentes web para aumentar la accesibilidad

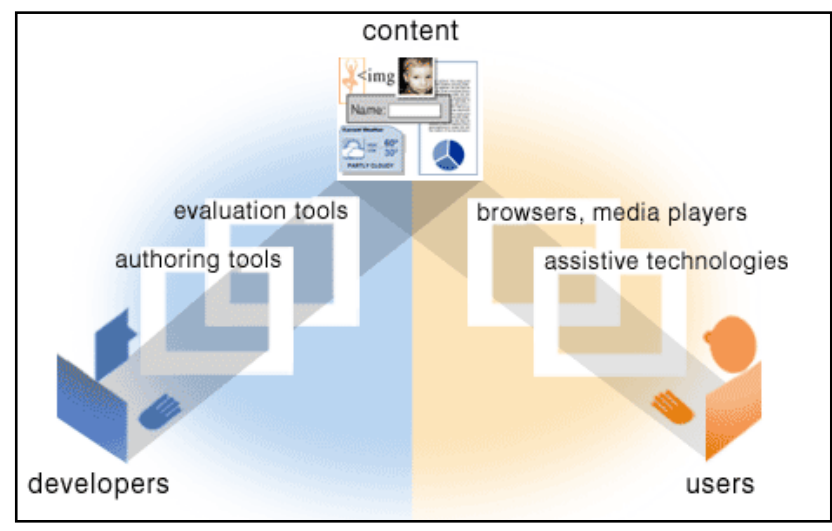

Fuente: W3C

Las directrices de accesibilidad que definen cada uno de estos elementos son desarrollados por el Consorcio World Wide Web (W3C) dentro de la Iniciativa de Accesibilidad de Web (WAI). Estas directrices se dividen en tres grandes apartados: 
A. Directrices de accesibilidad de diseño y creación web (ATAG)

Estas directrices exponen los instrumentos de creaciones de páginas web, de modo que sean las personas con discapacidad quienes creen el contenido web, o bien, puedan ayudar a los diseñadores a crear un contenido más accesible. Estas directrices se engloban dentro de un estándar normativo técnico (ATAG 2.0) y proporcionan el marco y los criterios para conseguir el éxito.

B. Directrices de accesibilidad de contenido web (WCAG)

Estas directrices explican cómo hacer el contenido web más accesible a las personas con discapacidad. El contenido web generalmente se refiere a la información de una página web o el uso web de ésta, incluyendo: texto, imágenes, sonidos, estructura y presentación. De esta forma, se convierte especialmente útil para los creadores web, los creadores de instrumentos de evaluación web o entidades o personas que necesitan un estándar de accesibilidad web. En este sentido, el contenido web no debe ser sólo a través de un lenguaje simple, sino que se deben proporcionar mecanismos comprensibles para navegar dentro de éste y entre sus páginas.

El WCAG es un estándar técnico que se basa en 12 normas que se resumen en cuatro principios: perceptible, operable, comprensible y robusta. Para cada pauta, hay criterios de éxito que se clasifican en tres niveles: A, AA, y AAA, al igual que ocurría con el ATAG.

C. Directrices de accesibilidad de los usuarios (UAAG)

Hacen referencia a cómo hacer usuarios accesibles, prestando especial interés a los usuarios con discapacidad. Entre los elementos que interactúan en estas directrices encontramos a los navegadores web, usuarios web o complementos tecnológicos, como el software que algunas personas con discapacidad usan en su interacción con la web.

Gracias a estas directrices podemos conocer las necesidades de diferentes públicos, ya que nos permiten saber si el usuario tiene acceso a todo el contenido a través de teclado o la web, el control del usuario sobre el contenido, así como sobre el interfaz, entre otras. Las UAAG están siendo desarrolladas para ayudar a hacer las futuras generaciones de navegadores web más accesibles, proporcionar la información alternativa basada en la tecnología de usuarios y la plataforma, y alinearse con las WCAG 2.0 y las ATAG 2.0. 


\subsection{Directrices de Accesibilidad de Contenido Web (WCAG)}

Como hemos comentado, las WCAG son un estándar técnico que se basa en 12 normas que se resumen en cuatro principios y 12 pautas:

\begin{tabular}{|c|c|c|}
\hline PRINCIPIOS & \multicolumn{2}{|r|}{ PAUTAS } \\
\hline \multirow{4}{*}{$\begin{array}{l}\text { Perceptible: } \\
\text { La información y los componentes } \\
\text { de la interfaz de usuario deben ser } \\
\text { presentados a los usuarios de modo } \\
\text { que ellos puedan percibirlos. }\end{array}$} & $\begin{array}{l}\text { Alternativas } \\
\text { textuales }\end{array}$ & $\begin{array}{l}\text { Proporcionar alternativas textuales para } \\
\text { todo contenido no textual (textos } \\
\text { ampliados, braille, voz, símbolos). }\end{array}$ \\
\hline & $\begin{array}{l}\text { Medios } \\
\text { tempo- } \\
\text { dependientes }\end{array}$ & $\begin{array}{l}\text { Proporcionar alternativas para los medios } \\
\text { tempo-dependientes. }\end{array}$ \\
\hline & Adaptable & $\begin{array}{l}\text { Crear contenido que pueda presentarse } \\
\text { de diferentes formas. }\end{array}$ \\
\hline & Distinguible & $\begin{array}{l}\text { Facilitar a los usuarios ver y oír el } \\
\text { contenido. }\end{array}$ \\
\hline \multirow{4}{*}{$\begin{array}{l}\text { Operable: } \\
\text { Los componentes de la interfaz de } \\
\text { usuario y la navegación deben ser } \\
\text { operables. }\end{array}$} & $\begin{array}{l}\text { Accesible por } \\
\text { teclado }\end{array}$ & $\begin{array}{l}\text { Proporcionar acceso a toda la } \\
\text { funcionalidad mediante el teclado. }\end{array}$ \\
\hline & $\begin{array}{l}\text { Tiempo } \\
\text { suficiente }\end{array}$ & $\begin{array}{l}\text { Proporcionar a los usuarios el tiempo } \\
\text { suficiente para leer y usar el contenido. }\end{array}$ \\
\hline & Convulsiones & $\begin{array}{l}\text { No diseñar contenido de un modo que } \\
\text { podría provocar ataques, espasmos o } \\
\text { convulsiones. }\end{array}$ \\
\hline & Navegable & $\begin{array}{l}\text { Proporcionar medios para ayudar a los } \\
\text { usuarios a navegar, encontrar contenido y } \\
\text { determinar dónde se encuentran. }\end{array}$ \\
\hline \multirow{3}{*}{$\begin{array}{l}\text { Comprensible: } \\
\text { La información y el manejo de la } \\
\text { interfaz de usuario deben ser } \\
\text { comprensibles. }\end{array}$} & Legible & $\begin{array}{l}\text { Hacer que los contenidos textuales } \\
\text { resulten legibles y comprensibles. }\end{array}$ \\
\hline & Predecible & $\begin{array}{l}\text { Hacer que las páginas web aparezcan y } \\
\text { operen de manera predecible. }\end{array}$ \\
\hline & $\begin{array}{l}\text { Entrada de } \\
\text { datos asistida }\end{array}$ & $\begin{array}{l}\text { Ayudar a los usuarios a evitar y corregir } \\
\text { los errores. }\end{array}$ \\
\hline $\begin{array}{l}\text { Robusto: } \\
\text { El contenido debe ser } \\
\text { suficientemente robusto como para } \\
\text { ser interpretado de forma fiable por } \\
\text { una amplia variedad de aplicaciones } \\
\text { de usuario, incluyendo las ayudas } \\
\text { técnicas. }\end{array}$ & Compatible & $\begin{array}{l}\text { Maximizar la compatibilidad con las } \\
\text { aplicaciones de usuario actuales y } \\
\text { futuras, incluyendo las ayudas técnicas. }\end{array}$ \\
\hline
\end{tabular}

Fuente: W3C 
Estas 12 pautas asociadas a los cuatro principios, no son medibles en sí mismas, sino que proporcionan los objetivos para hacer el contenido accesible y sirven para comprender los criterios de conformidad e implementarlos.

Cada una de estas pautas, además, tiene asociados una serie de criterios de conformidad que se han de cumplir y que sí son medibles. Los criterios de conformidad están ordenados según su nivel de cumplimiento asociado ( $A, A A$ y $A A A)$ :

- Nivel de conformidad "A": Los puntos de control con prioridad $1^{3}$ están satisfechos.

- Nivel de conformidad "Doble-A": Los puntos de control con prioridad 1 y $2^{4}$ están satisfechos.

- Nivel de conformidad "Triple-A": Todos los puntos de control de prioridad 1, 2, y $3^{5}$ están satisfechos.

Teniendo en cuenta estas directrices podremos analizar el diseño web de algunas páginas españolas en las que se cumplen estos criterios de conformidad para comprender en qué consisten.

\section{Ejemplos de buenas prácticas}

En este último punto, se han escogido cinco portales web que cumplen el nivel de conformidad Triple A. Para dicha elección se han seleccionado portales de entidades de diferente personalidad jurídica, así como de distintos sectores empresariales. Entre la selección están la enseñanza (pública y privada), los servicios comerciales, así como entidades de atención al público tanto de personalidad societaria como de fundación. Todas ellas son entidades alejadas del colectivo de personas con discapacidad en valor de su mayor concienciación sin pertenecer a la comunidad.

\footnotetext{
${ }^{3}$ Prioridad 1: Un diseño web debe satisfacer este punto de control, ya que si no fuera así el contenido web sería de acceso imposible para ciertos colectivos. Estamos, por tanto, ante una exigencia básica.

${ }^{4}$ Prioridad 2: Un diseño web debe satisfacer este punto de control. La satisfacción de este grupo de control quitará barreras significativas para acceder a ciertos contenidos web.

${ }^{5}$ Prioridad 3: Si no se tiene en cuenta este punto de control, algunos grupos de usuarios podrían tener problemas en acceder a la información web. Si se tiene en cuenta este punto se mejorara el acceso a contenidos web.
} 


\subsection{Caso 1:Adecco}

Adecco es una multinacional que ofrece "servicios de empleo temporal, empleo fijo, externalización de servicios, consultoría y recolocación." 6 Es una compañía que se encuentra entre las 500 mejores empresas de la lista Fortune Global. ${ }^{7}$

Cuenta en la actualidad con más de 300 oficinas en toda España, más de 14.600 clientes en todos los sectores y más de 30.000 personas empleadas diariamente, sólo en España. ${ }^{8}$

Respecto a la empresa en Internet, Adecco España cuenta con dos webs paralelas, una para los usuarios sin problemas de accesibilidad $^{9}$ y otra para aquellos con problemas de accesibilidad. ${ }^{10}$ La versión accesible es una réplica casi exacta de la otra versión. En ningún momento se ha realizado una web más simplificada. Los contenidos provienen del mismo gestor, de tal modo que se asegura la coherencia y actualización de los mismos en ambas webs. Por este motivo, la web dispone de alternativas accesibles a nivel (AAA) en todos los contenidos y, por tanto, incluye el logo del W3C-WAI nivel AAA en su versión WCAG 1.0.
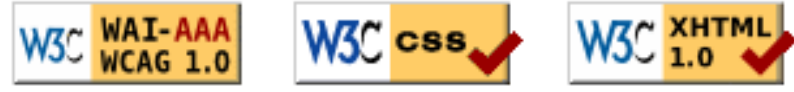

Además, existe enlace entre las dos páginas, no sólo entre las homes. Aun así, la página de entrada de la web común se ha desarrollado con el nivel básico de accesibilidad (A). De tal forma que incluso la web para usuarios sin problemas de accesibilidad sea cómoda de igual manera para los usuarios con discapacidad.

Las características más importantes de la web para usuarios con discapacidad son: se puede visualizar perfectamente en todo tipo de navegadores puesto que utilizan hojas de estilo que cumplen el estándar CSS 2.1 y CSS 3.0; mediante el teclado se puede acceder a la totalidad de los menús de la web sin la necesidad de usar el ratón; tanto las imágenes como todos los botones e iconos llevan textos explicativos del contenido de los mismos además de tener un tamaño optimizado para cualquier tipo de usuario; respecto al color, se convierte en un elemento completamente secundario, ya que la información es comprensible sin su

\footnotetext{
${ }^{6}$ Según la web de la compañía.

${ }^{7}$ Ver el listado completo de Fortune Global en http://money.cnn.com/magazines/fortune/global500/2013/full list/?iid=G500 sp full

${ }^{8}$ Las cifras en todo el mundo son: 5.500 oficinas en más de 60 países, con más de 100.000 clientes en todos los sectores y 700.000 personas empleadas diariamente.

${ }^{9}$ Ver http://www.adecco.es

${ }^{10}$ Ver http://www.adecco.es/Home/Home.aspx?Modo=Accesible
} 
utilización; además los textos tienen suficiente contraste con los fondos para aquellas personas con deficiencias visuales.

\subsection{Caso 2. Universidad CEU San Pablo}

La Universidad CEU San Pablo es una universidad privada, fundada hace 75 años. En la actualidad cuenta con más de 7.000 alumnos y un claustro docente de casi 900 profesores que imparten clases en estudios de grado y postgrado con un alto enfoque a los programas bilingües de miras a la internacionalización de sus estudios.

Respecto a su página web nos encontramos con un portal que ha seguido las directrices propuestas en la Iniciativa de Accesibilidad Web, (WAI, Web Accessibility Initiative). De tal forma que buscan que todos los usuarios, tengan o no discapacidad, puedan navegar sin problemas por la web. ${ }^{11}$

Para poder navegar por las secciones más importantes se han creado atajos de teclado que permiten acceder a las mismas sin la utilización del ratón. Además se puede usar el tabulador para el mismo fin, de tal forma que se puede recorrer el menú y todas sus opciones ordenadamente.

Por último, la web está condicionada para aquellos usuarios que tengan lectores automáticos de pantalla, de tal forma que no sea necesario escuchar todo el menú cada vez que cambian de página.

\subsection{Caso 3. Eroski Consumer}

La revista Eroski Consumer es una publicación perteneciente a la Fundación Eroski de la cooperativa del mismo nombre dedicada a la venta de productos alimenticios. En la actualidad, cuenta con más de 2.400 establecimientos repartidos por toda España. La revista Eroski Consumer es, según la propia web, "un medio de comunicación de referencia en el ámbito del consumo, cuyo objetivo es mantener informado al consumidor en el día a día a través de información útil y práctica”. ${ }^{12}$

Respecto a la accesibilidad, en su web muestran su voluntad de llegar al mayor número de usuarios puesto que como afirman resulta una tarea asequible para sus gestores de

\footnotetext{
${ }^{11}$ Ver la página web de la Universidad CEU San Pablo http://www.uspceu.es/

${ }^{12}$ Ver la página web de Eroski Consumer http://www.consumer.es/
} 
contenidos: "No es más caro ni más difícil construir una rampa que unas escaleras, pero no siempre se hace". Y es lo que hacen con su sitio web, una navegación sencilla apta para todos los usuarios, aunque tengan algún tipo de discapacidad.

Como las páginas anteriores, Eroski Consumer sigue casi todas las directrices de la iniciativa WAI con los siguientes estándares (XHTML 1.1, CSS y WAI-AAA).

Las características funcionales de esta web son las siguientes: funcionamiento en todos los navegadores; sistema de navegación simplificado con una estructura coherente en todo el sitio web; atajo con el teclado; vínculos relacionados agrupados; diseño elástico, no sólo del texto, sino del tamaño de la web al completo; los enlaces tienen aclaraciones que ayudan a saber dónde llevan. Además, con algunos navegadores (JAWS, Home Page Reader, Lynx y Opera) permiten desplegar una lista de enlaces para facilitar la navegación al usuario.

\subsection{Caso 4. Fundación Oftalmológica del Mediterráneo}

La Fundación Oftalmológica del Mediterráneo (FOM) ${ }^{13}$ es la entidad jurídica que gestiona el Centro Superior de investigación, docencia y asistencia oftalmológica de la Comunidad Valenciana desde 2005. Según su página web su fin primordial es "el impulso, la promoción y el favorecimiento de la investigación científico-técnica en el ámbito de la medicina oftalmológica, el desarrollo de nuevas tecnologías diagnósticas y terapéuticas, la atención en general de la salud ocular (...), así como la cooperación al desarrollo de terceros países en materia socio-sanitaria".

Como vemos se trata de una fundación que entre sus usuarios va a contar con numerosas personas con discapacidad visual. Este hecho obliga a que su página web sea, si cabe, más proclive a tener una buena accesibilidad para todo tipo de público. La página web cumple todos los requisitos de accesibilidad de la norma UNE 139803:2004. Además, cumple los criterios de verificación de nivel triple A definidos en WCAG 1.0 por la Iniciativa de Accesibilidad Web (WAI) del Consorcio World Wide Web (W3C).

Entre las características que presenta la página web de la FOM se encuentra la posibilidad de navegar mediante un dispositivo de voz por toda la web. Como en las anteriores web, se permite navegar por la web sin necesidad de utilizar el ratón y se puede visualizar desde diferentes navegadores. Utiliza numerosos objetos diseñados con flash, pero no todos ellos llevan a un nivel de interactividad AAA debido a, como ellos mismos reconocen en la web,

\footnotetext{
${ }^{13}$ Ver la página web de la Fundación Oftalmológica del Mediterráneo (FOM) http://www.fom.es/es/
} 
"las carencias en la interoperabilidad entre sistemas y dispositivos a las que se enfrenta esta tecnología en la actualidad".

Por último, cabe destacar en esta web, lo que ellos denominan "web de baja visión”. En ella, las personas con visión reducida pueden utilizar herramientas y dispositivos que les ayudarán en su vida cotidiana. En la parte superior de dicha web encontramos un cuadro de mandos que permiten una accesibilidad mayor, si cabe, a la web. Mediante este cuadro de mando se puede cambiar completamente la imagen de la web, desde el tamaño del texto hasta el color del fondo y el texto de tal forma que cada usuario lo adecue a sus posibilidades.

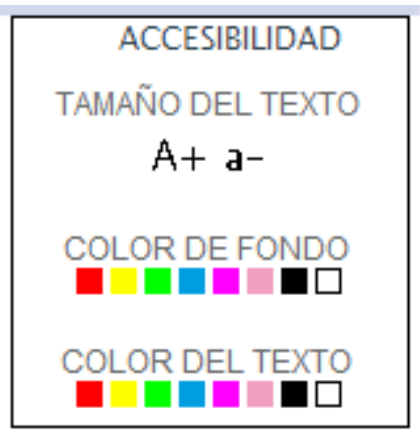

Fuente: Fundación Oftalmológica del Mediterráneo

\subsection{Caso 5.Instituto de Enseñanza Secundaria Atenea}

Por último, presentamos la web del Instituto de Enseñanza Secundaria Atenea, ${ }^{14}$ ubicado en la localidad de San Sebastián de los Reyes en Madrid. Se trata de un pequeño instituto que ofrece clases tanto de Enseñanza Secundaria Obligatoria (ESO) como de Bachilleratos (de Humanidades y CC. Sociales y de Ciencias y Tecnologías).

La web de este instituto ha seguido las pautas para conseguir un diseño para todos o universal atendiendo a los niveles de triple A (W3C WAI-AAA WCAG 1.0). Las pautas que han seguido para cumplir con las directrices de accesibilidad son las siguientes: correcta visualización con cualquier tipo de navegador; diseño homogéneo y minimalista con un lenguaje claro y sencillo y un uso de simbología estándar y fácil de entender por todos.

\footnotetext{
${ }^{14}$ Ver la página web del Instituto de Enseñanza Secundaria Atenea http://www.educa.madrid.org/Web/ies.atenea.sansebastian/
} 
Por su parte, se han utilizado las propiedades de Accesskey y Tabindex, usadas también en las páginas anteriores, que posibilita la navegación usando únicamente el teclado para ayudar a aquellos alumnos/as con problemas de carácter motórico que dificultan la utilización del ratón. Además, se incluye una tabla con las combinaciones más usuales para navegar con mayor facilidad por las páginas de la web.

\begin{tabular}{|c|c|}
\hline \multicolumn{2}{|c|}{ Teclas de acceso rápido } \\
\hline Epígrafes del Menú principal & $\begin{array}{l}\text { Epígrafes que aparecen en el } \\
\text { Menú de los Departamentos }\end{array}$ \\
\hline Inicio & $\begin{array}{ll}\text { Libros } & \text { L }\end{array}$ \\
\hline Nuestro Instituto & ESO \\
\hline Secretaría & Bachillerato \\
\hline Servicios & Profesores \\
\hline Enseñanzas & Actividades \\
\hline Planes y Proyectos & \multirow[t]{2}{*}{ Enlaces } \\
\hline Departamentos & \\
\hline Alumn@s & En el $D^{\circ}$ de Física y Química \\
\hline Actividades & $\begin{array}{ll}\text { Galería } & \mathrm{G}\end{array}$ \\
\hline Tablón de Anuncios & \multirow[t]{2}{*}{ Historia de la Ciencia } \\
\hline Revista & \\
\hline Mapa del Sitio & En el $D^{\circ}$ de Tecnología \\
\hline Accesibilidad & \multirow[t]{2}{*}{ Proyectos } \\
\hline @Webmaster & \\
\hline & En el $D^{\circ}$ de Orientación \\
\hline Enlaces externos & Orientación Académica y Profesional 1 \\
\hline $\begin{array}{ll}\text { EducaMadrid } & \mathrm{Z}\end{array}$ & Formación Profesional 2 \\
\hline \multirow[t]{5}{*}{ Comunidad de Madrid $\mathrm{Y}$} & Acceso a la Universidad \\
\hline & Aprende a Estudiar \\
\hline & Enlaces \\
\hline & Materias Docentes \\
\hline & EEES (Plan de Bolonia) \\
\hline
\end{tabular}

Fuente: Instituto de Enseñanza Secundaria Atenea

También, cabe destacar la utilización de texto adicional en todas las imágenes e iconos para facilitar la descripción de todos los elementos, para ello se ha utilizado la herramienta "longdesc". Además, se ha tenido en cuenta los problemas que aporta el uso de Javascript, por lo que se ha evitado su utilización.

Por último, respecto a los colores se ha buscado siempre el contraste entre el color de fondo y del texto. Incluso permite visualizar la página en blanco y negro para una correcta lectura. 


\section{Conclusiones}

El diseño web debe tener como fin primero los usuarios. Las creaciones van a ser utilizadas por un público que debe alcanzar el máximo nivel de satisfacción en la interactuación con la web. En su labor, los diseñadores web han de atender a la principal característica que van a tener los usuarios, la diversidad. Los individuos pueden presentar diferentes capacidades funcionales, que no deben influir en la utilización web ni en el acceso a los contenidos, para ello se deben seguir las premisas del diseño para todos. Un diseño sin barreras de accesibilidad universal.

Para lograr ese diseño universal, el World Wide Web Consortium (W3C) desarrolla protocolos y directrices estándares para que cualquier persona independientemente de su capacidad pueda acceder a la herramienta web. Esta comunidad internacional que vela por asegurar el desarrollo de la web a largo plazo, tiene como principios la web para todo el mundo y la web desde cualquier dispositivo. El W3C trabaja en las directrices de accesibilidad que se engloban en la Iniciativa de Accesibilidad Web (WAI). Como comentamos anteriormente, estas directrices se agrupan en tres; de diseño y creación web, de los usuarios y de contenido web, que son los puntos en los que se ha centrado el análisis que se ha presentado en este trabajo.

Algunos de los sitios web que han obtenido nivel de conformidad "Triple-A" son los de Adecco, la Universidad CEU San Pablo, la Fundación Oftalmológica del Mediterráneo, Eroski Consumer y el Instituto de Enseñanza Secundaria Atenea. Estas páginas web, en general, ofrecen alternativas de texto al contenido en audio, atajos de teclado sin usar el ratón, lenguaje claro y sencillo, cuidan el color y tienen un diseño elástico en el tamaño de la web al completo y, en el texto, se puede aumentar o disminuir la letra para su mejor visualización.

Aunque estas directrices tienen como finalidad permitir a las personas con discapacidad acceder a la web y a su contenido, no son ellas las únicas que se benefician. Personas mayores con alguna deficiencia fruto del envejecimiento, personas no familiarizadas con el uso de estas herramientas o personas que no conocen nuestro idioma, encontraran facilidades para poder navegar por la red.

El cumplimiento de estas directrices ofrece una serie de ventajas a todos los usuarios y, también, a los propietarios de los portales al mejorar en posicionamiento web, en usabilidad, en eficiencia, en aumento del número de visitas, en la reducción de costes y en el afianzamiento de la imagen de la empresa. 
Para finalizar, es de subrayar la percepción que como personas sin discapacidad hemos tenido al interactuar con las web que cumplen en nivel alto las pautas. Podemos afirmar que no hemos encontrado diferencias en el uso de los portales, el contenido, el diseño, etc. Se ha interactuado como con el resto de portales. No hay pérdida alguna, pero sí muchas ganancias. Siempre se habla de la maximización de beneficios, si se sigue este objetivo en el diseño web, es necesario cumplir las directrices de accesibilidad web.

El diseño para todos es ventajoso en varios aspectos y es un factor de integración de las personas con discapacidad al facilitar el acceso a la web y sus contenidos en igualdad de condiciones. Derecho reconocido que debe ser respetado. Todo ello, caminando para llegar a la meta de una sociedad inclusiva en la que la diferencia sea un factor de suma, no de resta.

\section{Bibliografía}

Anula, A. (Dir.) (2011). Convención Internacional de Naciones Unidas sobre los Derechos de las Personas con Discapacidad en Fácil Lectura. Madrid: Real Patronato sobre Discapacidad y Grupo DILES.

Chisholm, W. y Vanderheiden, G. (1999). Web Content Accessibility Guidelines 1.0. W3C. Recuperado el día 15 de enero de 2014 de http://www.w3.org/TR/WAlWEBCONTENT/\#wc-priority-1.

Consorcio World Wide Web (2014). Recuperado el día 14 de enero de 2014 de http://www.w3.org.

Ley 51/2003, de 2 de diciembre, de igualdad de oportunidades, no discriminación y accesibilidad universal de las personas con discapacidad (BOE núm. 289, de 3 de diciembre de 2003). Recuperado el día 8 de enero de 2014 de http://www.boe.es/boe/dias/2003/12/03/pdfs/A43187-43195.pdf.

Organización de Naciones Unidas (ONU) (2006). Convención sobre los Derechos de las Personas con Discapacidad. Nueva York: ONU. Recuperado el día 8 de enero de 2014 de http://www.un.org/esa/socdev/enable/documents/tccconvs.pdf.

Real Decreto 1494/2007, de 12 de noviembre, por el que se aprueba el Reglamento sobre las condiciones básicas para el acceso de las personas con discapacidad a las tecnologías, productos y servicios relacionados con la sociedad de la información y medios de comunicación social (BOE núm. 279, de 21 de noviembre de 2007). Recuperado el día 8 de enero de 2014 de http://www.boe.es/boe/dias/2007/11/21/pdfs/A47567-47572.pdf. 
Universidad de Alicante (2014). "Accesibilidad Web". Recuperado el día 8 de enero de 2014 de http://accesibilidadWeb.dlsi.ua.es/.

Forma de citar este artículo en bibliografías

MADRIGAL BARRÓN, P., CARRILLO PASCUAL, E. y PUEBLA MARTÍNEZ, B. (2014): EI diseño web como factor de integración de las personas con discapacidad, en Revista PANGEA, 5, páginas 1 a 21. Red Académica Iberoamericana de Comunicación. Recuperado el de 2 de: http://www.revistapangea.org 